\title{
EEG FINDINGS IN POSTERIOR FOSSA TUMORS ।
}

\author{
B. K. Bagchi, Ph.D., R. L. Lam, M.D., ${ }^{2}$ K. A. Kool, M.D. \\ and R. C. BAssetr, M.D. \\ Laboratories of Electroencephalography and Neuropathology of the Neuropsychiatric \\ Institute and the Department of Surgery, University of Michigan Medical School, \\ Ann Arbor, Michigan
}

It is generally accepted that existence of a posterior fossa tumor may greatly complicate interpretation of the electroencephalogram. In particular many difficulties arise in evaluating for a particular case the varied ways in which the expansion of an infratentorial lesion can lead to change in the record of cerebral activity. Certain parts of the cerebrum, such as the inferior margins of temporal and occipital lobes, at times, are subject to the direct stresses of tumor growth. Progressive obstruction of the ventricular system is also known to produce significant cerebral alteration; and finally involvement of cerebello-cerebral pathways and the brain stem reticular formation may significantly influence the brain wave pattern to suggest lateralization of dominant activity.

The reports of different investigators on the EEG changes in posterior fossa tumors verified by operation or autopsy are quite diverse and offer no definite criteria for their localization. Smith et al. (1940) found in four lateralized cases dominant parietooccipital deltas with homolateral emphasis in three and bilateral emphasis in one, so did Holland (1941) in his two cases though with an indefinite lateralization. Lennox and Brody (1946) reported bilateral or shifting frontal and/or temporal deltas in three cases. Bickford and Baldes (1947) noted generalized paroxysmal slow or fast waves unrelated to the tumor foci in 94 per cent of their 50 cases. In six cases, apparently normal waves were recorded by

\footnotetext{
${ }^{1}$ Financed in part by the University of Michigan Horace H. Rackham Fund. Project No. 231.

2 Now in Washington University School of $\mathrm{Me}$ dicine, St. Louis, Missouri.
}

Walter (1936, 1936 1937) and in three by Davidoff (in Smith et al. 1940). The latter author, however, found generalized abnormal waves in one case and frontal abnormal activity in another case. False hemispheric localization in 19.5 per cent of 86 posterior fossa lesions was reported by Hoefer et al. (1946). No statement was made as to whether the remaining tumors showed homolateral localization or no localization. It was added that 7 out of 28 acoustic tumors showed false localizing signs usually in the contralateral temporal area; what other tumors did or did not show was not mentioned. Walter (1938) noted delta foci on the same side of a few tumors, as did Witwer et al. (1943) in one case. Walter and Dovey (1944) found in two cases bilateral $4-7 \mathrm{sec}$. rhythm on an automatically analyzed record from posterior regions, in one of them more from the same side of the lesion. Lairy-Bounes and Fischgold (1950) in their study of 38 cases recorded normal patterns in 11, generalized. abnormal patterns in 18, and frontal or occipital slow waves in 9. Rheinberger and Davidoff (1942) found in their 13 lateralized cases contralateral EEG emphasis in 4, homolateral emphasis in 6 and no lateralization in 3. Lyman (quoted in Rheinberger and Davidoff 1942) could not discover any consistent correlation between EEG changes and 16 cases. Walker (1941) considered EEG diagnosis insufficient in 10 posterior fossa tumors. Williams and Gibbs (1938) and Gibbs (in Smith et al. 1940) doubted the value of EEG in posterior fossa localization. The conclusion at which Rheinberger and Davidoff arrived (1942), namely, "there is no pattern or distribution of electrical ab- 
normality specifically indicative of posterior fossa disturbance" has been tacitly accepted as valid.

In this study we review the pertinent clinical material observed in our laboratory studies and histopathology were considered with relation to EEG alterations. As the study progressed an attempt was made to perfect the recording procedure on the basis of experience gained in the earlier cases.
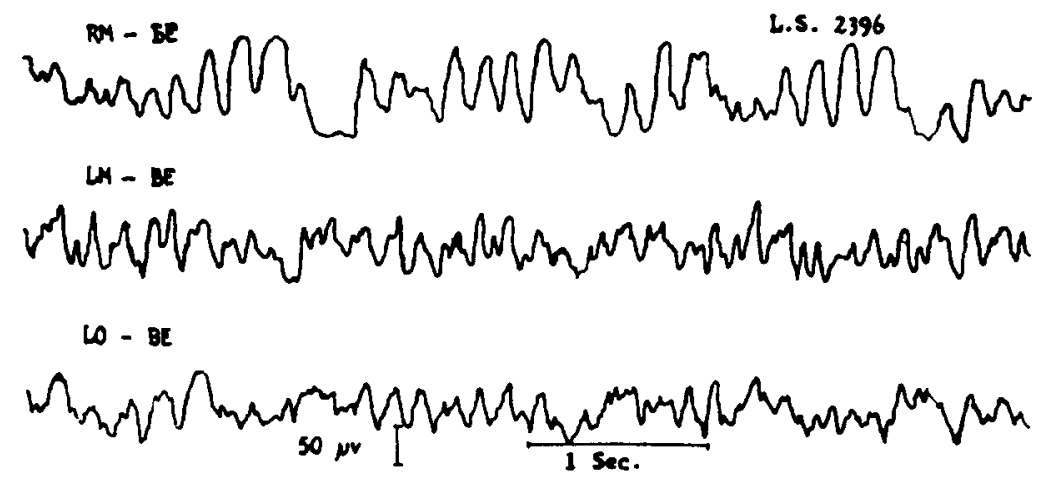

A. LEFT CEREDELLAR HEMUETOBLASTOMA

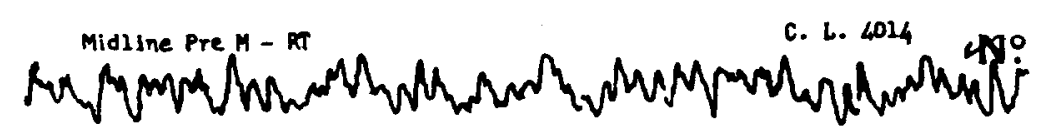

Midline Pre M - L Post. T
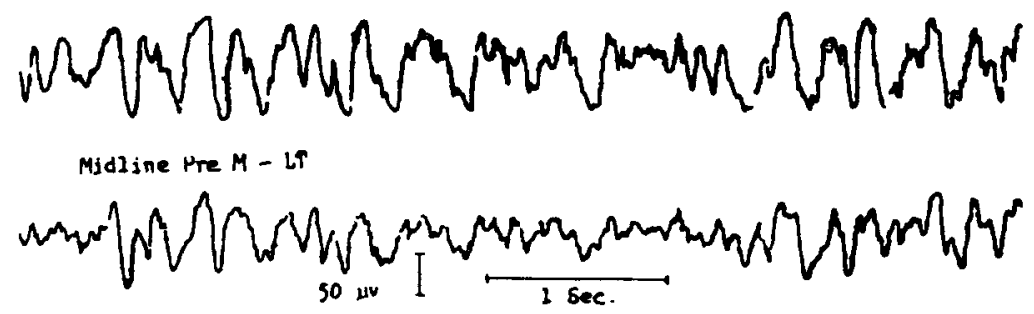

B. RIGHT CEREBELLAR HEMAGIOBLASTOMA

Fig. 1

A. Case 20. Left cerebellar hemangioblastoma. Age 38, confused, mild papilledema, moderate ventricular dilatation. Note right sided emphasis in background and burst voltage and deltas (strip 1). B. Case 18. Right cerebellar hemangioblastoma. Age 33, semi-comatose, marked papilledema, mild ventricular dilatation. Note left sided emphasis in background and burst voltage and deltas (strips 2 and 3 ). The distribution of the waves (motors, occipitals and temporals) on each of these two early cases in which the workup was incomplete, threw doubt on the existence of a superficial circumscribed cortical lesion and raised a suspicion about a deep lesion but its significance in relation to a contralateral posterior fossa lesion was not realized when the records were taken over 5 years ago. RM - right motor, LM - left motor, LO - left occipital, BE - both ears, Pre $\mathrm{M}$ - premotor, RT - right temporal, L Post T - left posterior temporal, LT - left temporal. Voltage and time calibrations are marked on this and succeeding figures.

over a seven year period and attempt to set up some tentative empirical EEG criteria for localization under certain clinical reservations. In each case, the clinical course, air

\section{METHOD}

The preoperative EEGs of 37 patients with posterior fossa tumor were studied. In all cases surgical confirmation was obtained. 
Histological diagnosis was available in 34 of the 37 cases. Clinicopathological data included: age of patient, duration and nature of symptoms, presence and degree of papilledema and other evidences of increased intracranial pressure, pattern of neurological deficit, X-ray findings, and the estimated
Three, six or eight channel records were obtained on Grass electroencephalographs. Two-thirds of the cases had a routine or semi-localizing examination only; the latest one-third were studied by a more elaborate technique now in use in this laboratory. The routine study comprised records between
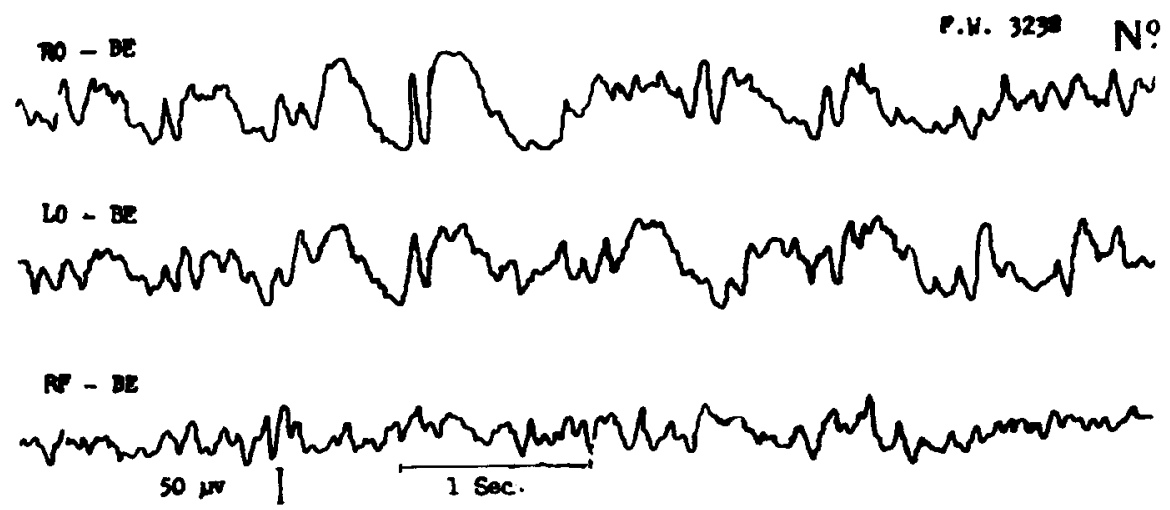

A. RIGH CEREBULAR MEDULLOUSTOM

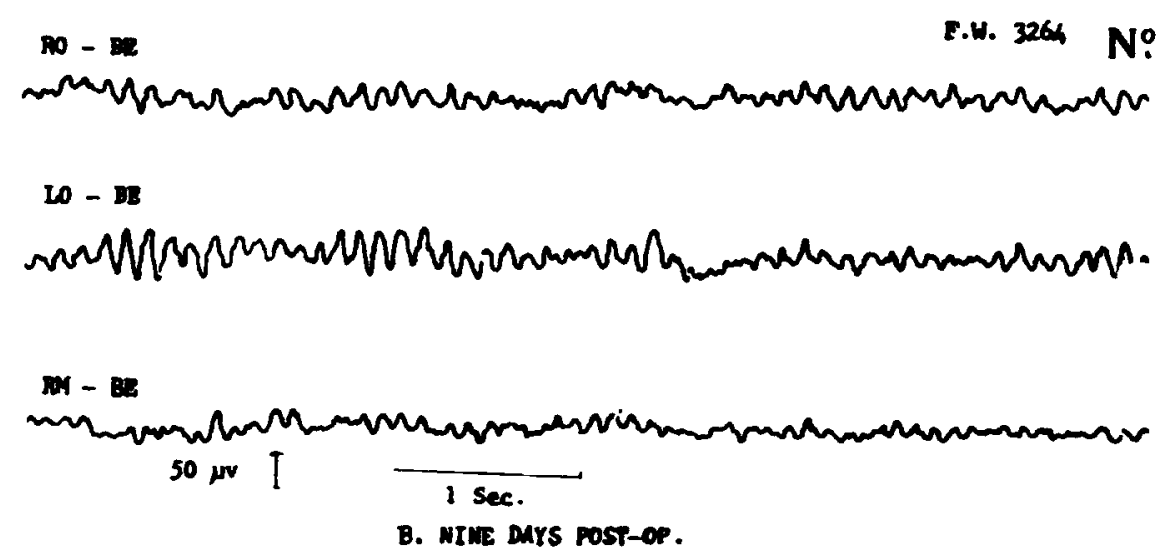

Fig. 2

Case 17. Large medulloblastoma right cerebellum. Age 29, clear sensorium, mild papilledema and ventricular dilatation. Three channel recording (1-22-1944). A. Note abortive spike-and-waves and about 1 and $11 / 2 / \mathrm{sec}$. waves in both occipitals. These waves in addition to delta waves in both motor and premotor regions (not shown here) argue against a superficial localized cortical lesion. B. Normal waves with minor voltage difference following operation.

size, location and growth characteristics of the tumor. Ventriculograms on 32 patients were used to establish correlations between the extent of ventricular dilatation and displacement and the amount of background and paroxysmal EEG change. each of 8 scalp leads ( 1 to 8 ) and interconnected (figs. $3 a$ and 9 ) as well as separate ear leads (fig. $3 b$ and $c$, left ear reference is not shown). Scalp to scalp records were also obtained between antero-posterior, latero-medial, latero-posterior 
(figs. 4a and 6) and coronal combinations. For more detailed study a full 8 channel localizing examination supplemented the routine and followed the rationale discussed in detail by Bagchi et al. (1947). Bagchi and Bassett (1947), and Bassett and Bagchi point in connection with routine and additional leads of the anterior and posterior quadrants (fig. 7, lateral aspect of posterior quadrants).

For further detailed recordings, the scalp was subdivided into small triangles measur-

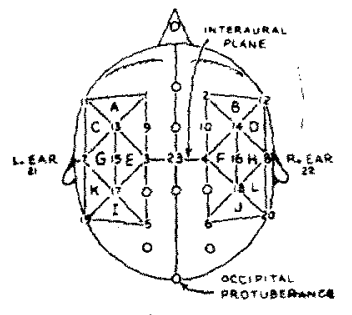

A
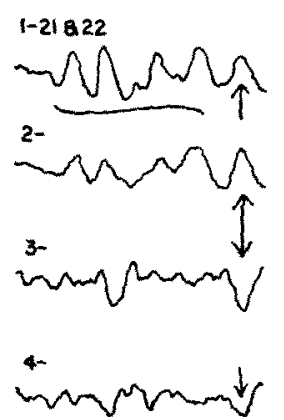

5

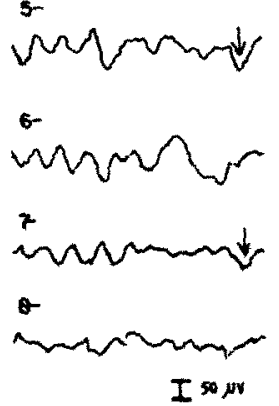

220
B

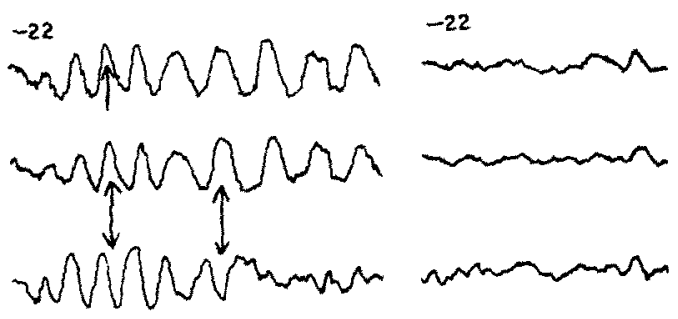

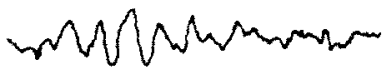

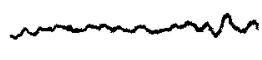

whorrarer

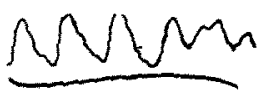

onymenarem
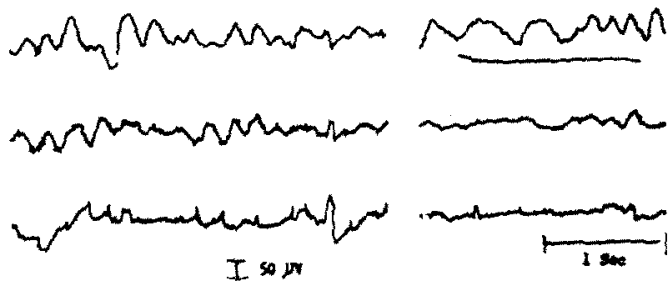

218

Fig. 3

Case 4. Large medulloblastoma in vermis. IV ventricle and right cerebellum. Age 41/2, lethargic, minimal papilledema and moderate ventricular dilacation. A. Routine monopolar recording shows slow background and 3/sec. bilateral bursts, especially in frontals, probably slightly more on left (underlined strip 1). Questionable contralateral cerebral emphasis. Arrows indicate genuine phase reversal between frontals and other areas. This phenomenon is found inconstantly, rarely, and in short sections in only some posterior fossa lesions. B. Bilateral synchronous 3 to $4 / \mathrm{sec}$. bursts most prominent in both frontal and motor areas. C. Note that after about 20 sec. frontals and motors show no bursts but both parieto-occipitals do, more emphasized in the left parieto-occipital (underlined strip 5). Bilateral bursts particularly parasagittally, inter-areal asynchrony. intra-areal variability, contralateral cerebral emphasis in voltage, incidence or wave length, and genuine phase cilference are some of the findings in posterior fossa localization. Sheet numbers are at bottom to indicate interval between sections $A, B$ and $C$. The interval between sections $B$ and $C$ in round numbers omitting fractions of 10 sec. which comprise a sheet is 2 sheets $(248-246)$, i.e. $20 \mathrm{sec}$. $(2 \times 10 \mathrm{sec})$. Sheet numbers are given at bottom of most of the othir figures.

(1948). The usefulness of alternate ear leads proposed then has since been confirmed experimentally in the dog (Lennox and Epstein, 1950). The full localizing examination included among other setups, the use of the vertex lead as a reference ed from fixed points. The arms of the triangles (shown in insets) corresponded exactly for the two sides of the head in length and location. Scalp to scalp tracings were taken between homologous combinations upon the two sides, and scalp to ear 
between the individual points and interconnected or separate ear leads. Sometimes due to differences in interelectrode distance and in the degree of cancellation of potentials the same abnormal areas may give slightly different information when linked with different neighboring or distant areas with different degrees of involvement. Thus, similar vectors were recorded between these and a selection of scalp leads.

A certain variation of the localization scheme outlined briefly above was particularly useful in the posterior fossa study. Using frontal ( 1 and 2), premotor (9 and $10)$, parieto-occipital (5 and 6) and interaural-temporal ( 7 and 8 ) leads against

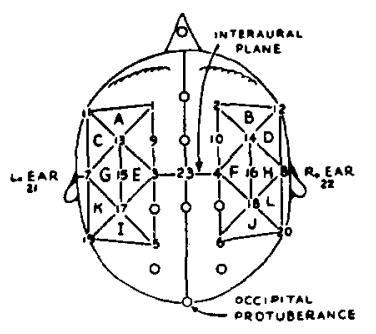

Routine Bipolar

A

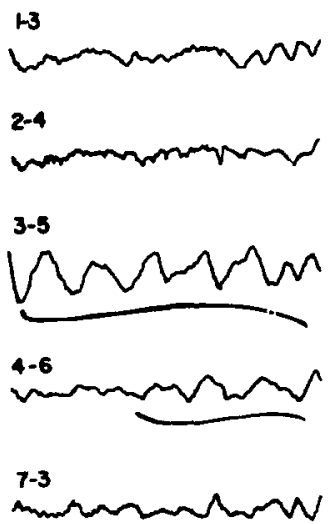

8-4

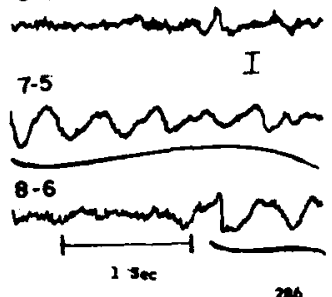

Anterlor Qundrants (eonoposer)

$\mathbf{B}$

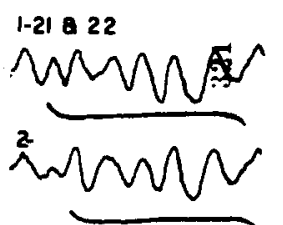

9-

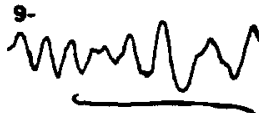

10.

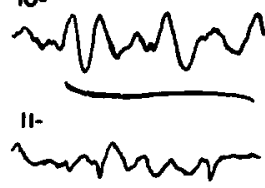

C

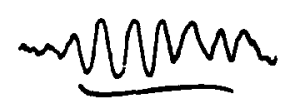

12.

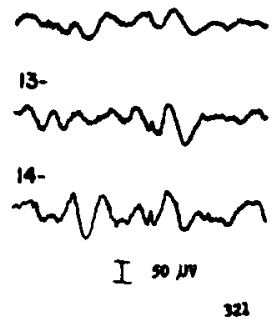

22
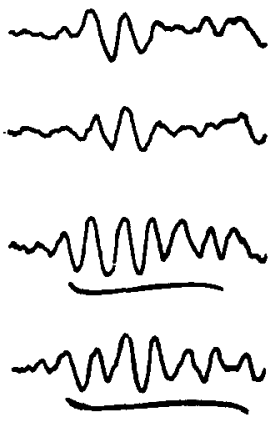

7.6. cans
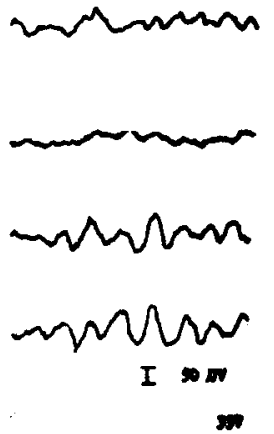

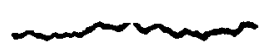

Fig. 4

Same case as in figure 3. A. Routine bipolar recording shows predominantly left-sided bursts (contralateral cerebral emphasis), about $2.5 / \mathrm{sec}$. (underlined strips 3 and 7 ). B. Monopolar recording of anterior quadrants shows higher and greater bursts in frontals and premotors (i.e. anterior parasagittal concentration) like in B, figure 3 , (strips 1 to 4), than in lateral areas (leads $11,12,13$ and 14) with interconnected ear reference leads. C. Note about $160 \mathrm{sec}$. later lesser voltage and incidence of frontal bursts (variability), (strips 1 and 2 ).

to obtain an adequate sampling for each area, permitting the detection of transient as well as continuously evident patterns and distinguishing between apparently equipotentia! regions, numerous combinations must be used. Low cervical, occipital protuberance, and nasal electrodes were sometimes used as extra reference points, and interconnected ear leads, the latter two combinations were replaced successively by the remaining homologous lead combinations. This modification allowed detection of synchrony or asynchrony between bursts recorded from homologous frontal and premotor areas on the one hand and parietooccipital, true occipital and lateral areas on 
the other. Triangulations (fig. 5B, triangle G; fig. 11, triangles $C$ and $D$ ) and other components of the bipolar workup $(1-3,2-4$, $3-5,4-6,7-3,8-4,7-5,8-6$ combinations, figs. $4 a, 6,8 a)$ were sometimes of greater value in demonstrating shifting or lateralized dominance. (large cystic left cerebellar hemangioblastoma) was associated with only 1 of these; 3 of the other 4 arose in the cerebellopontine angle and 1 was a cholesteotoma of ventricle IV. Based on a classification of the tumors into parenchymatous and extraparenchymatous types, only 1 of the 28
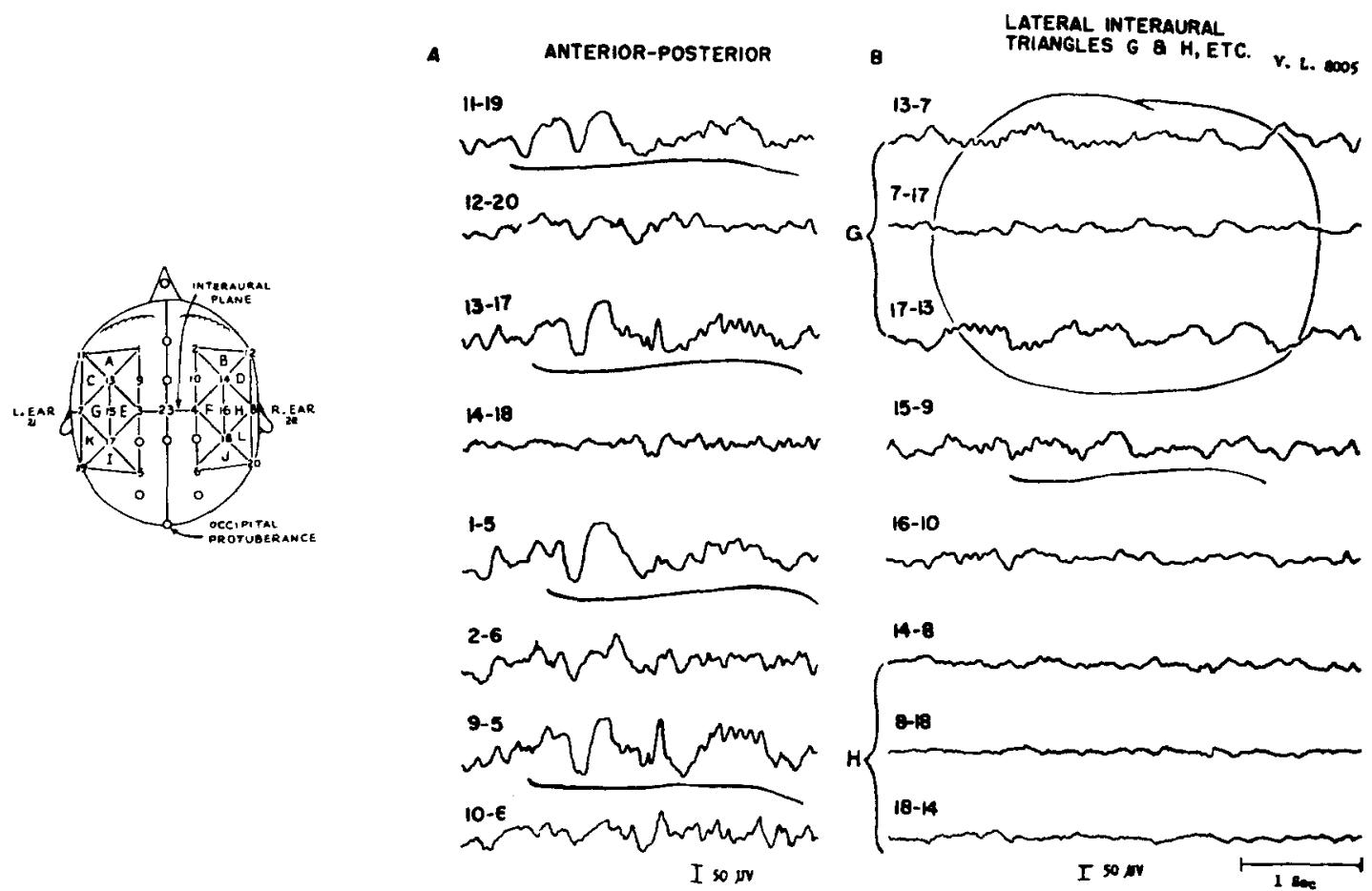

4.

Fig. 5

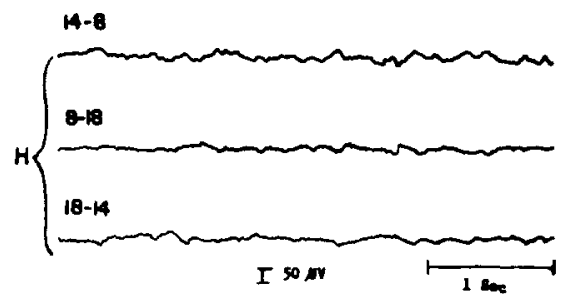

4s1

Same case as in figures 3 and 4. A. Antero-posterior bipolar recording from routine and localizing leads emphasizes $11 / 2$ to $2 /$ sec. bursts on the left side during light sleep (underlined strips $1,3,5$ and 7 ), confirming left sided cerebral emphasis found before in waking. B. Left interaural lateral triangle, $G$ (strips 1,2 and 3 ) shows during light sleep bursts of $1 \frac{1}{2}$ to $2 / \mathrm{sec}$. not found in the corresponding triangle on the right side, triangle $H$ (strips 6,7 and 8 ) further indicating left sided emphasis. Of the two additional bipolar recordings (strips 4 and 5) the left one (strip 4) shows higher and more deltas. Occasional shift to the right side found in this case is not shown here. The combined EEG findings enumerated in captions of figures 3,4 and 5 and also the shift phenomenon (not shown here) in a case without convulsive disorder and other conditions mentioned under control data, were empirically interpreted to be a presumptive evidence of some deep midline lesion or abnormality in or near posterior fossa. more on the right.

\section{RESULTS}

1. Correlations between severity of EEG changes and site of tumor in posterior fossa. No record from this series of 37 patients was convincingly normal. However, 5 representing 13.5 per cent of the total, were borderline slow. A parenchymatous tumor parenchymatous tumors showed a borderline record, whereas 4 of the 9 extra-parenchymatous tumors were in that group. All of the tumors associated with borderline records were non-malignant but the reverse was not true.

Thirty-two patients of the series 
per cent) had definitely abnormal records. showing background slowing, or burst activity of different types or both. Only 5 of this more markedly disordered group had extraparenchymatous tumors, all of which were non-malignant; the larger remainder had parenchymatous tumors, 15 of which were malignant. The trend therefore is bilaterally synchronous bursts of different types and degrees (figs. 3B; 4B and $\mathrm{C}$; 9; $10 \mathrm{~A})$. Twenty-five of 28 laterally situated tumors with or without extension to involve midline structures showed contralateral dominance (or emphasis) with respect to incidence, voltage or duration of waves occurring during bursts (figs $1 \mathrm{~A}$, strip 1; 1B.

TABLE I

\section{DISTRIBUTION OF BURST ACTIVITY IN RELATION TO THE LOCATION OF POSTERIOR FOSSA TUMORS}

\begin{tabular}{|l|c|c|c|c|c|}
\hline \multicolumn{1}{|c|}{ LOCATION } & \multicolumn{2}{|c|}{ EMPHASIS } & \multicolumn{2}{c|}{ SHIFT } & \multicolumn{2}{c|}{$\begin{array}{c}\text { Bilaterally } \\
\text { synchronous }\end{array}$} & $\begin{array}{c}\text { Total number } \\
\text { of cases }\end{array}$ \\
\hline \multicolumn{1}{|c|}{ Parenchymatous } & Right & Left & & $11,17,18,22$, & 6 \\
\hline $\begin{array}{l}\text { Right } \\
\text { hemisphere }\end{array}$ & 0 & $\begin{array}{c}11,17,18, \\
22,23,36\end{array}$ & 22,36 & 23,36 \\
$\begin{array}{l}\text { Midline and right } \\
\text { hemisphere }\end{array}$ & 0 & $3,4,7,8,9$ & $4,7,13$ & $3,4,7,8,9,13$ & 8 \\
Left hemisphere & $13,27,33$ & 27,33 & 27,33 & \\
Midline and left \\
hemisphere
\end{tabular}

' Figures such as 11, 17 refer to case numbers. The authors' reprints will incorporate elaborate clinical material and EEG findings on each case. Only cases 25 and 5 did not show any lateralized emphasis. Cases 1 and 29 showed ipsilateral emphasis, and cases 2 and 21 no bilaterally synchronous burst. There was some question about extension of the lesion to the angle and right side of the pons in case 11 .

toward the association of less evident EEG change with tumors of the extraparenchymatous group (see Lairy-Bounes and Fischgold 1950). This trend should be checked on a larger number of extraparenchymatous tumors.

Table I summarizes the character of burst activity associated with tumors of the posterior fossa. Thirty-five of the 37 showed strips 2 and $3 ; 3 A$ and $C ; 4 A ; 5 A$ and $B$; $8 \mathrm{~A} ; 9 ; 11 \mathrm{ii} ; 12 \mathrm{~A} ; 13)$. Such dominance was always determined from the overall characteristics of the record, and was evident with both extraparenchymatous and parenchymatous tumors. It was especially notable with bipolar recordings including triangulation.

Twenty-one tumors of the entire series. 
including those with and without clearly lateralized dominance, showed shift of bursts from side to side from minimal to marked degree (figs. $6 ; 7 \mathrm{~B} ; 8 \mathrm{C} ; 11$ i). Such shift became evident in any one particular epoch of recording or when different epochs of recording were compared; therefore, overall dominance was decided only after a survey of all the epochs of a record. Some of the tumors studied early that did not show shift had incomplete EEG studies, hence lack of detection of shift might not ne- dominance or by shift in emphasis of bursts. The same is true for degree of background slowing. However, amount of contralateral dominance or emphasis was in some individual cases a differentiating clue between a midline and a lateralized tumor.

There were many individual variations in wave frequency, in voltage, in incidence of burst activity, in contra or homolateral dominance, in inter-areal asynchrony and intra-areal variability. There were also variations in the areas which showed the most

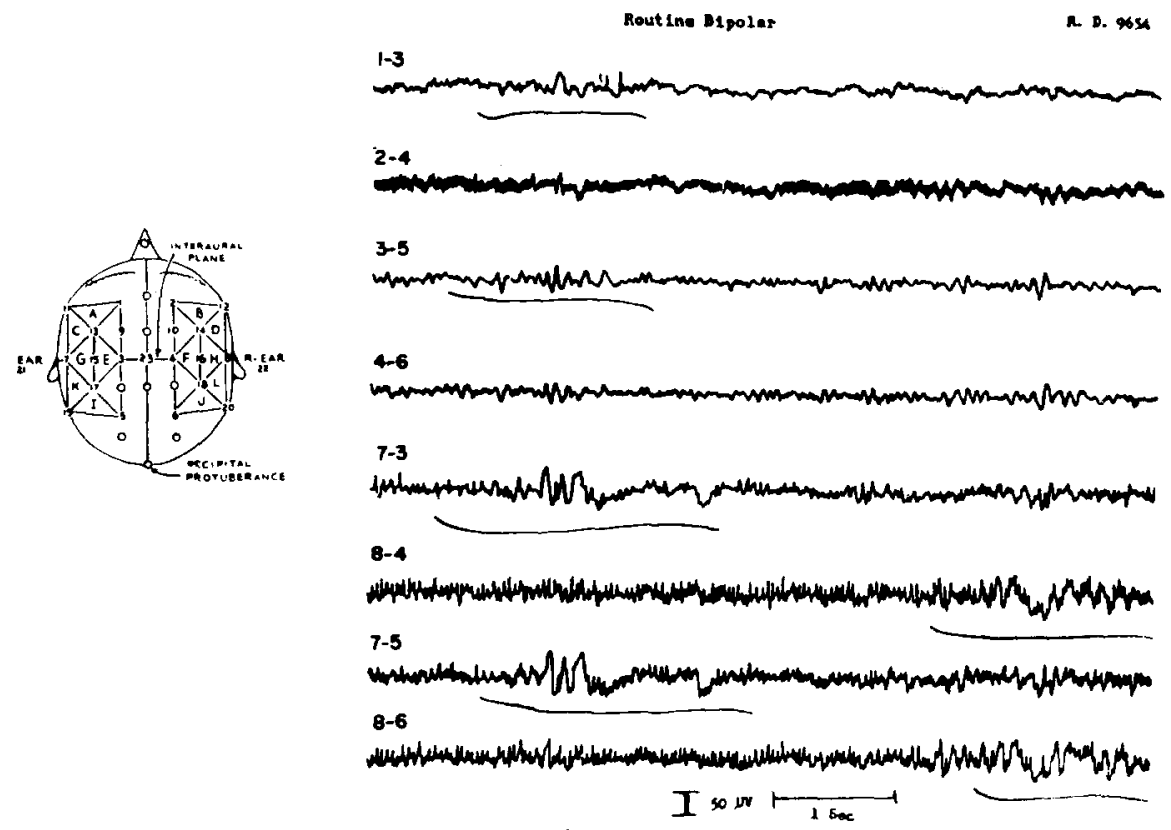

Fig. 6

Case 35. Moderate sized right cerebello-pontine ang'e acoustic neurinoma. Age 31 , clear sensorium, moderate papilledema and ventricular dilatation. First series of underlined waves (strips $1,3,5$ and 7 ) show minor mixed bursts on the left side in routine bipolar recording, indicating contralateral cerebral emphasis and in about $3 \mathrm{sec}$. a shift of bursts to the right side (strips 6 and 8 ) is seen though not involving all the routine leads. Fast waves are muscle artifacts.

cessarily mean absence of shift. Among 9 midline tumors, 7 had right or left sided dominance and there were only 5 characterized by shift, all of them being parenchymatous. This was not significantly different from the findings in the principally lateralized group, thus it is evident that midline tumors as a group cannot be distinguished from hemispheral tumors by prominent findings and in the lead combinations which best brought them out. The tendency was evident for slow or positive or spikey 6 to $8 / \mathrm{sec}$. or even $8.5 / \mathrm{sec}$. burst activity to be recorded from the parasagittal region of the hemispheres (i.e. parasagittal concentration), but in different cases this might be more evident anteriorly or posteriorly. However, incidence of bilaterally 
synchronous burst activity in the anterior parasaggital region (Bassett and Bagchi 1948) was greater than or equal to that present in all other head regions in 22 of the cases (figs. 3B; 4B and C; 9, strips 1-6). Records were not judged in detail for the amount of inter-areal asynchrony or intraareal variability. Rare genuine phase difference of deltas (not instrumental phase difference) was observed in 8 cases (figs. $3 \mathrm{~A}$ and $\mathrm{B} ; 9 ; 10 \mathrm{~A})$. (Bassett and Bagchi 1948; Bagchi and Bassett, 1949). inspection of this data makes it evident that it is impossible to identify any factor or a combination of factors which is clearly responsible for the EEG findings in a particular case. Yet evaluation of each factor in terms of EEG change for the entire series has value in suggesting trends, if it is remembered that the number of cases reported is relatively small and there may be cumulative effect of the factors. Table III analyzes these factors for the adolescentadult group. No tabulation is provided for

TABLE II

CORRELATION OF DOMINANT BACKGROUND FREQUENCY AND BURST ACTIVITY WITH DIFFERENT VARIABLES IN 37 POSTERIOR FOSSA TUMORS

\begin{tabular}{|c|c|c|c|c|c|c|c|c|c|c|c|c|c|}
\hline 1 & 2 & $2 \mathrm{~A}$ & 3 & 4 & 5 & 6 & 7 & 8 & 9 & 10 & 11 & 12 & 13 \\
\hline 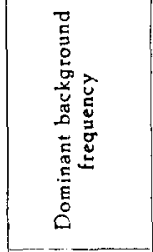 & 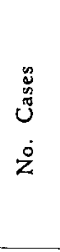 & 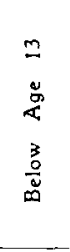 & 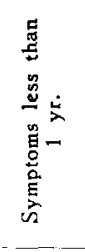 & 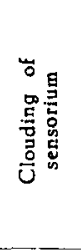 & 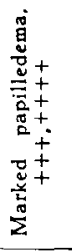 & 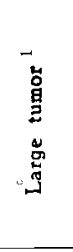 & 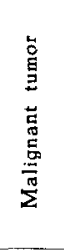 & 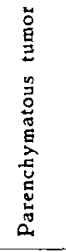 & 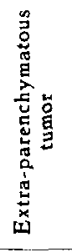 & 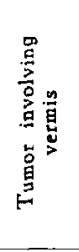 & 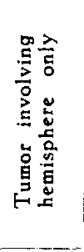 & 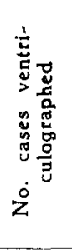 & 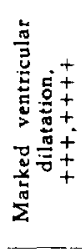 \\
\hline \begin{tabular}{|l}
$1-6 / \mathrm{sec}$ \\
$7-8 / \mathrm{sec}$ \\
$8.5-12 / \mathrm{sec}$ \\
and F
\end{tabular} & $\begin{array}{r}10 \\
8 \\
19\end{array}$ & $\begin{array}{l}7 \\
2 \\
1\end{array}$ & $\begin{array}{r}9 \\
6 \\
10\end{array}$ & $\begin{array}{l}7 \\
3 \\
1\end{array}$ & $\begin{array}{l}5 \\
1 \\
8\end{array}$ & $\begin{array}{r}10 \\
8 \\
15\end{array}$ & $\begin{array}{l}6 \\
3 \\
6\end{array}$ & $\begin{array}{r}9 \\
8 \\
11\end{array}$ & $\begin{array}{l}1 \\
0 \\
8\end{array}$ & $\begin{array}{l}7 \\
4 \\
6\end{array}$ & $\begin{array}{l}1 \\
4 \\
4\end{array}$ & $\begin{array}{r}8 \\
8 \\
16\end{array}$ & $\begin{array}{l}6 \\
4 \\
6\end{array}$ \\
\hline Total & 37 & 10 & 25 & 11 & 14 & 33 & 15 & 28 & 9 & 17 & 9 & 32 & 16 \\
\hline $\begin{array}{c}\text { Burst } \\
\text { Activity }\end{array}$ & & & & & & & & & & & & & \\
\hline $\begin{array}{l}\text { Mod. to } \\
\text { marked } \\
\text { Mild } \\
\text { None }\end{array}$ & $\begin{array}{r}19 \\
15 \\
3\end{array}$ & $\begin{array}{l}6 \\
3 \\
1\end{array}$ & $\begin{array}{r}12 \\
11 \\
2\end{array}$ & $\begin{array}{l}6 \\
4 \\
1\end{array}$ & $\begin{array}{l}8 \\
5 \\
1\end{array}$ & $\begin{array}{r}17 \\
14 \\
2\end{array}$ & $\begin{array}{l}7 \\
7 \\
1\end{array}$ & $\begin{array}{r}15 \\
12 \\
1\end{array}$ & $\begin{array}{l}4 \\
3 \\
2\end{array}$ & $\begin{array}{l}9 \\
8 \\
0\end{array}$ & $\begin{array}{l}5 \\
4 \\
0\end{array}$ & $\begin{array}{r}18 \\
13 \\
1\end{array}$ & $\begin{array}{r}11 \\
5 \\
0\end{array}$ \\
\hline Total & 37 & 10 & 25 & 11 & 14 & 33 & 15 & 28 & 9 & 17 & 9 & 32 & 16 \\
\hline
\end{tabular}

1 Diameier $3 \mathrm{~cm}$. or over.

Of the 16 cases of the entire series of 37, EEG localization was correct in 13. The earlier 21 cases formed the initial basis of the socalled criteria for localization.

2. Correlations with clinical and pathoanatomical data. Table II indicates a number of clinical, pathoanatomical and other factors in relation to background and burst activity for the series of 37 cases. Careful children because that group comprised only 10 cases.

Children with posterior fossa tumor were likely to show slower background activity for age than did adults, but their records did not differ from the latter in prominence of burst activity. There was no consistent relation between duration of symptoms and amount of burst activity in either child or 
adult groups. Clouding of sensation and impairment of consciousness appeared to be associated with degree of background slowing in both children and adults, but did not relate to prominence of burst activity. Neither the size of tumor nor the existence of malignant features related to degree of background slowing nor prominence of burst activity. The presence of moderate or marked papilledema showed no consistent emphasis in incidence, voltage or waveduration, shift, parasagittal concentration, anteriorly, posteriorly or both, inter-areal asynchrony and intra-areal variability of burst activity) were tested on an additional group of 49 consecutive cases which clinically suggested a deep lesion or had initial inconclusive diagnosis. Out of 11 verified posterior fossa cases and 1 deep anterior fossa case, preoperative EEG localization

TABLE III

CORRELATION OF DOMINANT BACKGROUND FREQUENCY AND BURST ACTIVITY WITH DIFFERENT VARIABLES IN 27 ADULT OR ADOLESCENT CASES

(13 years or over) WITH POSTERIOR FOSSA TUMORS

\begin{tabular}{|c|c|c|c|c|c|c|c|c|c|c|c|c|}
\hline 1 & 2 & 3 & 4 & 5 & 6 & 7 & 8 & 9 & 10 & 11 & 12 & 13 \\
\hline 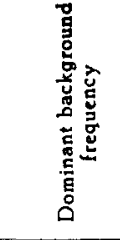 & $\begin{array}{l}\stackrel{ٌ}{0} \\
\stackrel{\tilde{J}}{0} \\
\dot{\dot{z}}\end{array}$ & 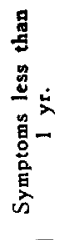 & 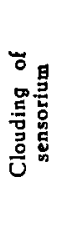 & 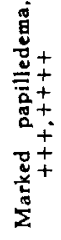 & 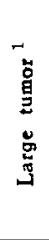 & 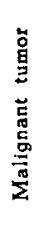 & 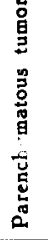 & 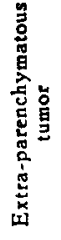 & 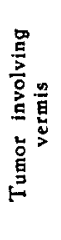 & 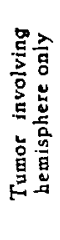 & 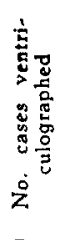 & 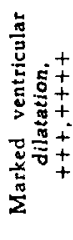 \\
\hline $1-6$ & 3 & 2 & 3 & 3 & 3 & 1 & 2 & 1 & 2 & 0 & 3 & 2 \\
\hline $7-8$ & 6 & 4 & 3 & 1 & 6 & 3 & 6 & 0 & 2 & 4 & 6 & 2 \\
\hline $\begin{array}{l}8.5-12 \\
\text { and } F\end{array}$ & 18 & 10 & 1 & 8 & 14 & 6 & 10 & 8 & 5 & 4 & 15 & 5 \\
\hline Total & 27 & 16 & 7 & 12 & 23 & 10 & 18 & 9 & 9 & 8 & 24 & 9 \\
\hline $\begin{array}{c}\text { Burst } \\
\text { Activity }\end{array}$ & & & & & & & & & & & & \\
\hline $\begin{array}{l}\text { Mod. to } \\
\text { marked }\end{array}$ & 13 & 7 & 4 & 7 & 11 & 5 & 9 & 4 & 4 & 4 & 12 & 5 \\
\hline Mild & 12 & 8 & 3 & 4 & 11 & 5 & 9 & 3 & 5 & 4 & 11 & 4 \\
\hline None & 2 & 1 & 0 & 1 & 1 & 0 & 0 & 2 & 0 & 0 & 1 & 0 \\
\hline Total & 27 & 16 & 7 & 12 & 23 & 10 & 18 & 9 & 9 & 8 & 24 & 9 \\
\hline
\end{tabular}

${ }^{1}$ Diameter $3 \mathrm{~cm}$. or over.

correlation with background slowing but questionable correlation with burst activity. Over the entire series moderate to marked ventricular dilatation was related to both degree of background slowing and to bursts; but if adult cases only were considered this relation was not evident.

3. Control data and clinical reservations. The so-called composite interpretative criteria (bilateral synchrony, overall unilateral was correct in 7, doubtful in 4 and wrong in 1 . In 17 unverified but clinically suspected cases of posterior fossa lesion, EEG localization agreed with clinical localization in 12 and was doubtful in 5 . The remaining 20 cases proved to have a variety of unrelated disorders. Besides this material, several thousand cases of epilepsy and several hundred cases of cerebro-vascular lesions, cortical atrophy and other abnormal- 
ities of the central nervous system were reviewed. The possibility of posterior fossa pathology in the last groups of cases was remote. Many of them, however, fulfilled all or some of the so-called EEG criteria for posterior fossa localization to some de- convulsive disorder, (2) temporal lobe seizure, (3) generalized cortical atrophy. (4) "degeneration", (5) cerebral arteriosclerosis, (6) hypertension and (7) acute vascular and traumatic conditions. In absence of these clinical conditions, the ful-
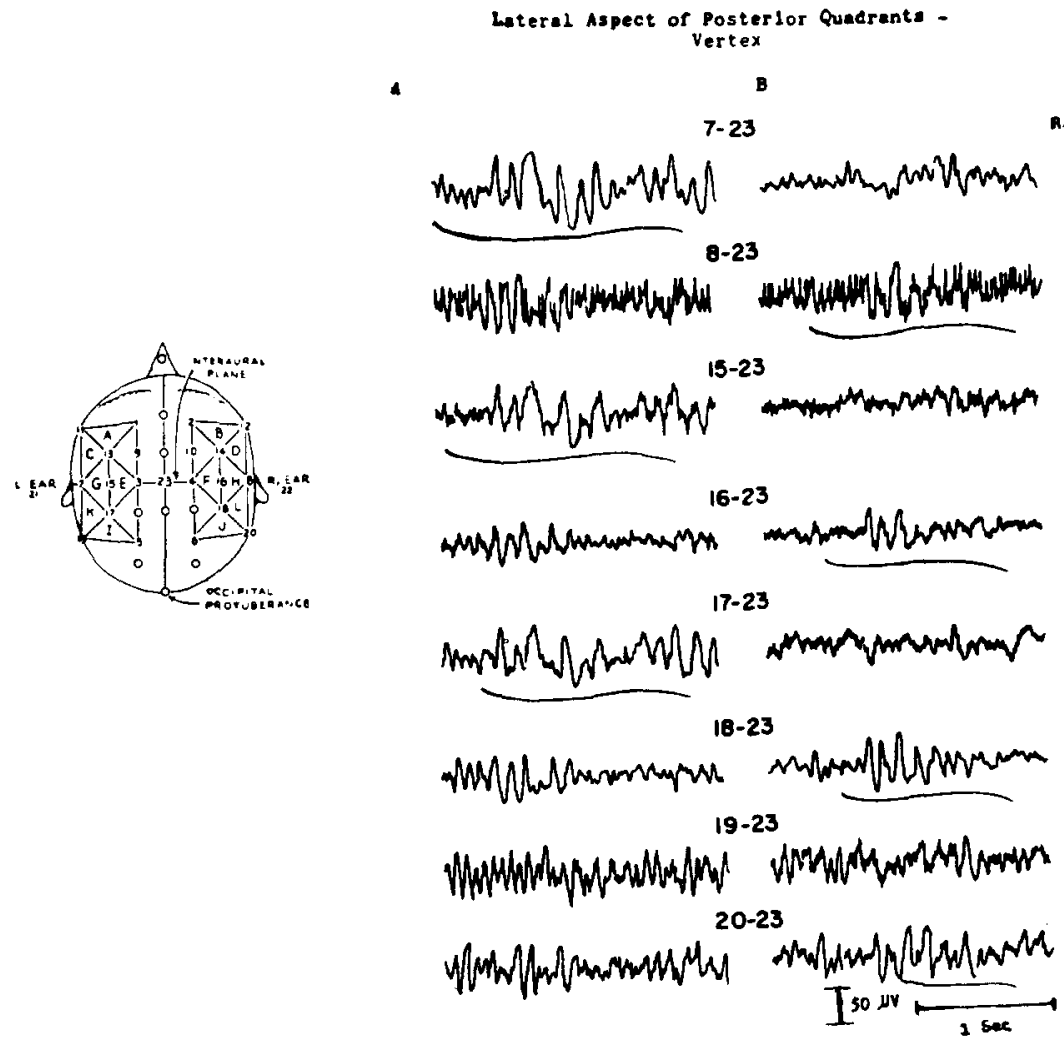

oro

012

Fig. 7

\begin{abstract}
Same case as in figure 6 . The sections $\mathrm{A}$ and $\mathrm{B}$, are taken within about $20 \mathrm{sec}$. with vertex as the reference lead. They show voltage increase and $71 / 2$ to $8 / \mathrm{sec}$. mixed bursts first in the lateral aspect of the posterior quadrant of the left hemisphere (underlined strips in $A$ ) then a shift of the same phenomenon to the lateral aspect of the corresponding quadrant of the right hemisphere (underlined strips in B) with an overall emphasis in the left (not entirely shown here). This shift phenomenon in conjunction with bilateral anterior parasagittal bursts, genuine phase reversal (neither is shown here) and left sided emphasis in a case without clinical convulsive disorder and other conditions (see control data) was interpreted as suggesting a deep lesion in or near posterior fossa more on the right.
\end{abstract}

gree. On the basis of this experience, the following clinical reservations were made in order to allow the question of the presence of a deep or posterior fossa lesion to be raised in a particular case on the basis of EEG alone: Absence of (1) idiopathic fillment of the composite EEG criteria should rouse a definite suspicion about the presence of a deep lesion, ${ }^{1}$ or a lesion in the

${ }^{1}$ A control study of tumors in thalamus, hypo thalamus, anterior and posterior third ventricle will be reported later. 
posterior fossa (see Bickford and Baldes 1947). Of course, such a diagnosis should be considered only after correlation of EEG findings with clinical history and neurological examination. the interpretation of electroencephalographic potentials.

Elevated cerebro-spinal fluid pressure is a common early finding in posterior fossa tumors. Compression of soft tissues, distor-

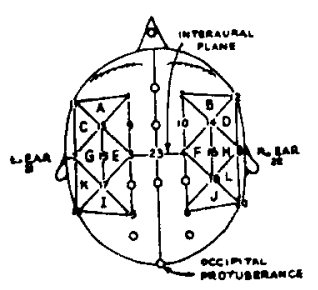

4

$1-3$

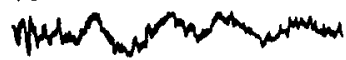

$2-4$

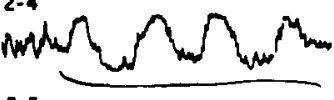

3-5

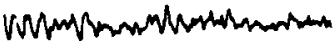

4-6

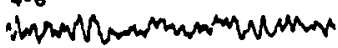

7-3

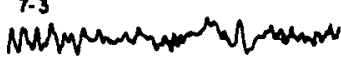

24

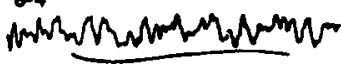

78

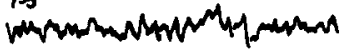

8-6

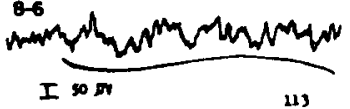

s

$|-2|$

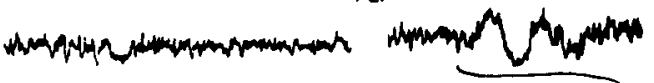

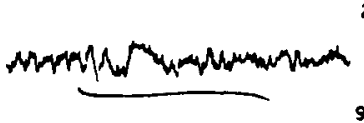

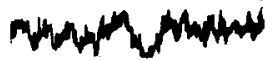

9

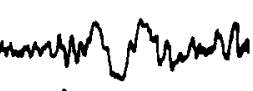

$10-$

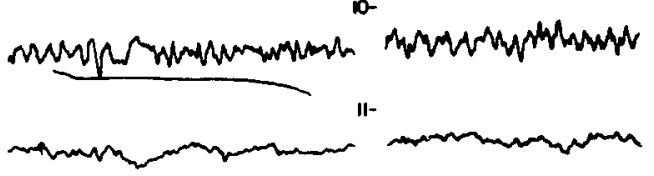

12 -

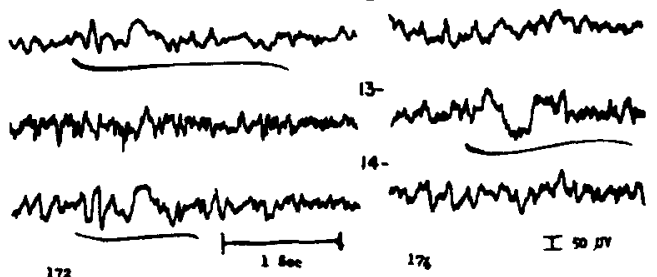

Fig. 8

Case 34. Large left sigmoid sinus and jugular bulb meningioma. Age 65, no papilledema, minimal ventricular dilatation and clear sensorium. A. Routine bipolar recording shows $1 \frac{1}{2}$ to 6 to $7 / \mathrm{sec}$. bursts on the right side, mostly right frontal (strip 2 also strips 6 and 8). B. Monopolar recording of anterior quadrant leads with left ear reference shows predominant mixed bursts ( 3 to $4 / \mathrm{sec}$.) in the underlined right anterior quadrant leads (strips 2, 4, 6 and 8). C. But in 20 sec., bursts shift to some left sided leads (strips 1,3 and 7) still involving the right frontal lead (strip 2). Lack of burst in lead 11 may be due to its short distance to left ear lead 21 (see figures 10 and 12, legends). Bilateral bursts, parasagittal concentration, shift of bursts to left, right sided emphasis. genuine phase reversal and some inter-areal asynchrony (the last two characteristics are not shown here) are overall findings interpreted as consistent with a lesion in or near posterior fossa more on the left.

\section{DISCUSSION}

The abnormal brain wave patterns in posterior fossa tumors are difficult to explain. Such patterns are considerably more indirect than those obtained in supratentorial lesions, and therefore represent a composite of reflected disturbances derived from deep-lying pathology. Increased intracranial pressure, compression of occipital lobes, and involvement of brain stem and adjacent cerebellar structures are possible mechanisms which may lead to confusion in tion of the ventricular system and subarachnoid spaces, interference with vascular supply by congestion and edema may exert a profound influence upon intracranial physiology. Since Walter (1936, 1936 1937) differentiated between tumor and pressure effects, considerable conflict has arisen regarding the specific relationship between pressure and the EEG. Williams (1939) considered edema in increased intracranial pressure responsible for the slow wave ab. normality seen in the EEG. On the other 
hand, Scarff and Rahm (1941) noted that ventricular decompression gave rapid disappearance of slow activity in their recordings. Stewart (1941) experimentally studying this problem, concluded that stretching of nerve fibers by internal hydrocephalus rather than increased intracranial pressure was responsible for slowing of EEG activity. Forster and Nims (1942) reported that in dilatation and a cloudy sensorium. Burst activity rather than background slowing was more common in cases with short duration of symptoms. Background slowing and burst activity were noted as being significantly greater in the younger age groups (see Lairy-Bounes and Fischgold, 1950).

In regard to the paroxysmal activity superimposed upon the disordered EEG of
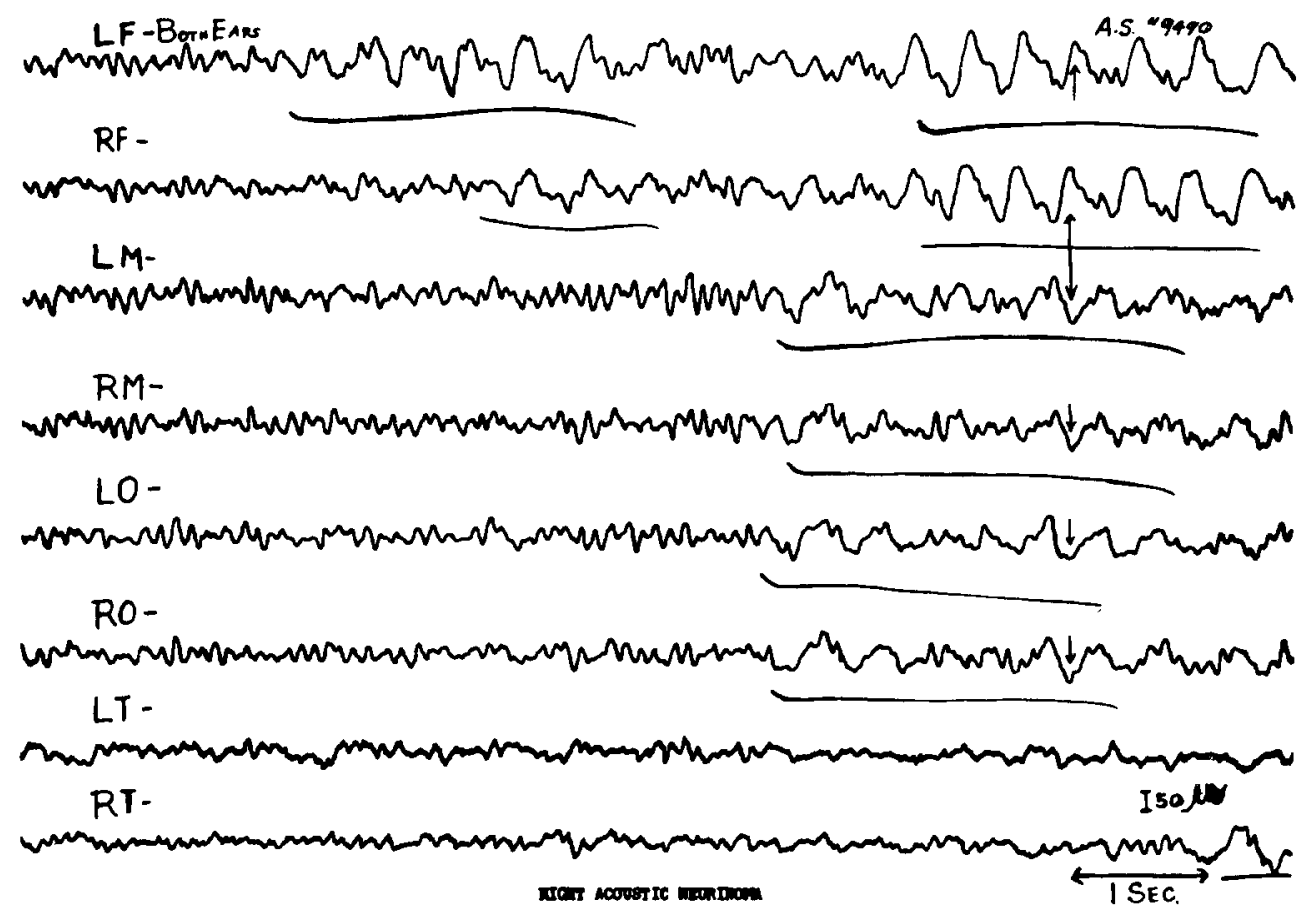

Fig. 9

Case 37. Right cerebello-pontine angle acoustic neurinoma. Age 62, clear sensorium, moderate papilledema and ventricular dilatation. Routine monopolar recording shows bilateral parasagittal bursts of $21 / 2$ to $3 / \mathrm{sec}$. anteriorly and posteriorly, except in temporals which are rarely represented at other times (not shown here) indicating intra-areal variability. Note also some genuine phase reversal between frontal and other areas, inter-areal difference in voltage and incidence and that the left frontal area is leading the others. Left sided emphasis in incidence and voltage in different recordings (strip 1) with right sided shift (not shown here) are other findings.

the laboratory animal, only pressures high enough to produce obstruction to blood flow would cause changes in the brain wave pattern. In the presence of space-occupying pathology, such a phenomenon certainly is not confirmed clinically.

In our series, background slowing and burst activity appeared most often in the cases with the most marked ventricular posterior fossa tumors. Bickford and Baldes (1947) suggested that such burst phenomenon (particularly 2-6/sec.) might result from excessive diencephalic discharges initiated by an expanding third ventricle. This is not confirmed clinically in all cases, as six of our cases with no papilledema and mild ventricular dilatation showed marked burst characteristics in the EEG. On the 
other hand, two cases showed marked ventricular dilatation but very little burst activity. Further, contralateral EEG dominance cannot be explained on the basis of this hypothesis.

Delta occipital frequencies were frequently seen in our series and in those re- ported in the literature (Holland 1941; Rheinberger and Davidoff 1942; Smith et al. 1940; Walter 1938; Walter and Dovey 1944). This may be due to compression of the immediate supratentorial structure from upward herniation of the brain stem and cerebellum and bulging of the tentorium

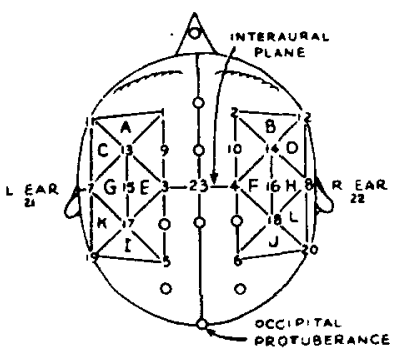

B

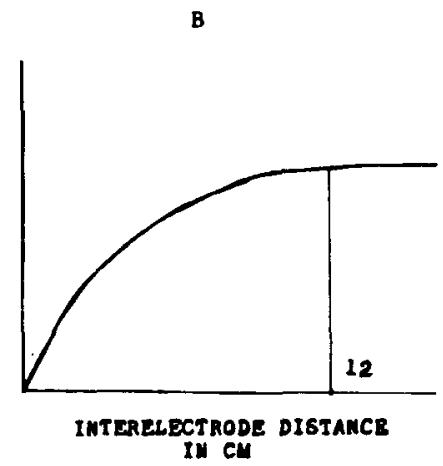

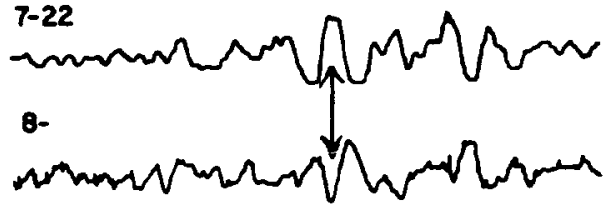
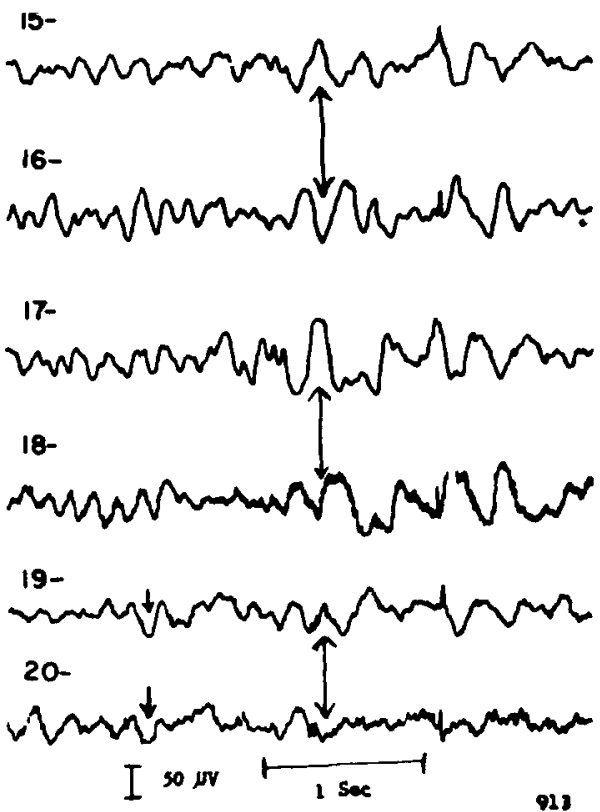

Fig. 10

Case 6. Large vermis medulloblastoma. Age 9, clear sensorium, moderate papilledema and mild ventricular dilatation. A. EEG shows 5 to $6 / \mathrm{sec}$. bursts rrom lateral aspect of the posterior quadrants of both hemispheres with right ear lead as reference. The arrows indicate genuine (not instrumental) phase reversal between homologous areas. The total EEG findings in this case are certainly not as striking as in some of the others. Nevertheless mild bilateral parasagittal bursts, mild right sided emphasis, rare left sided shift (not shown here) in addition to genuine phase reversal (indicated by arrows) created the suspicion about the existence of some deep midline abnormality or lesion more to the left. $B$. The curve indicates that normally voltage is a function of interelectrode distance between skull leads until 3 plateau is reached provided one disregards lobar specificity and individual difference. This relationship helps to correct for distance effect and estimate voltage gradient particularly in lateral areas with alternate car ground recording or bipolar recording from lead pairs having unequal distances (see legend, figure 12, $\mathrm{A}$ and $\mathrm{B}$ ). 
cerebelli, a not uncommon complication of posterior fossa space-taking lesions as emphasized by Ecker (1948).

In the light of recent experimental evidence, the influence of the cerebellum and the brain stem reticular formation on cor- stimulation of the neocerebellar cortex of the cat elicited high voltage fast discharges from the cerebral cortex, particularly from the opposite motor and premotor regions. Carraro and Gualtierotte (1940) later confirmed these findings. Henneman, Cook,

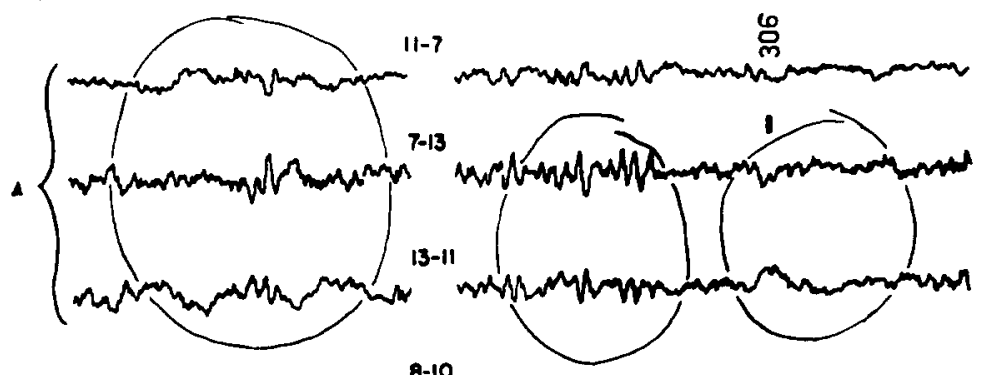

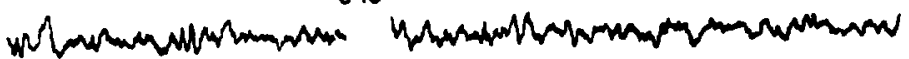

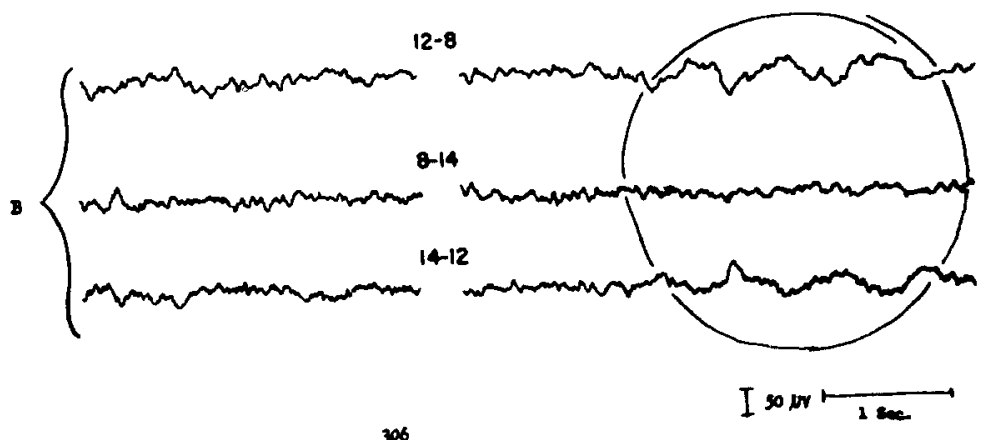

Fig. 11

Case 10. Large left cerebellar and vermian astrocytoma. Clear sensorium, mild papilledema, marked ventı1cular dilatation. (i) Ringed left anterior lateral triangle, A, probably shows more $11 / 2 / \mathrm{sec}$. waves than the corresponding triangle, $\mathrm{B}$, on the right; homolateral shift. (ii) Bilateral $11 / 2 / \mathrm{sec}$. bursts (instrumentally reversed) are seen within less then $10 \mathrm{sec}$., but with definitely more emphasis in the ringed right anterior lateral triangle, $\mathrm{B}$, (strips 5 and 7) than in the corresponding triangle, $\mathrm{A}$, on the left. This case shows no frontal, motor or premotor bursts like the other cases but instead shows bilateral bursts (1 to $2 / \mathrm{sec}$. and abortive spike-and-waves) in parieto-occipitals and true occipitals, and anterior and interaural temporals and lateral premotors, moderate right sided emphasis, mild left sided shift and some genuine phase reversal (not shown here).

ERROR: Triangles marked $\mathrm{A}$ and $\mathrm{B}$ in figure 11 should be marked $\mathrm{C}$ and $\mathrm{D}$.

tical activity must be considered in any attempt to clarify the basic factors behind the EEG of posterior fossa lesions. The predominant contralateral representation of the cerebellar hemispheres in the forebrain is at least consistent with the crossed EEG dominance seen in our cases of infratentorial tumors. Walker (1938) found that faradic and Snider (1948) have also shown extensive cerebello-cerebral connections using the evoked potential technique.

Investigations by Lindsley. Bowden and Magoun (1949) and Moruzzi and Magoun (1949) may be interpreted as suggesting that disturbances of the brain stem reticular formation either directly or indirectly in the 
presence of neoplasm may modify the final cortical brain wave pattern recorded in the EEG.

\section{SUMMARY}

1. EEG, clinical and pathoanatomical data are presented for 37 patients with posterior fossa tumors, verified at operation, in 34 cases with histological confirmation. (a) Slowing of the background pattern was usually associated with clouding of the sensorium, short duration of symptoms, and marked ventricular dilatation. This was most evident in children and often when the lesion was parenchymatous.

(b) The dominant cerebral change was noted contralateral to the tumor site in 25
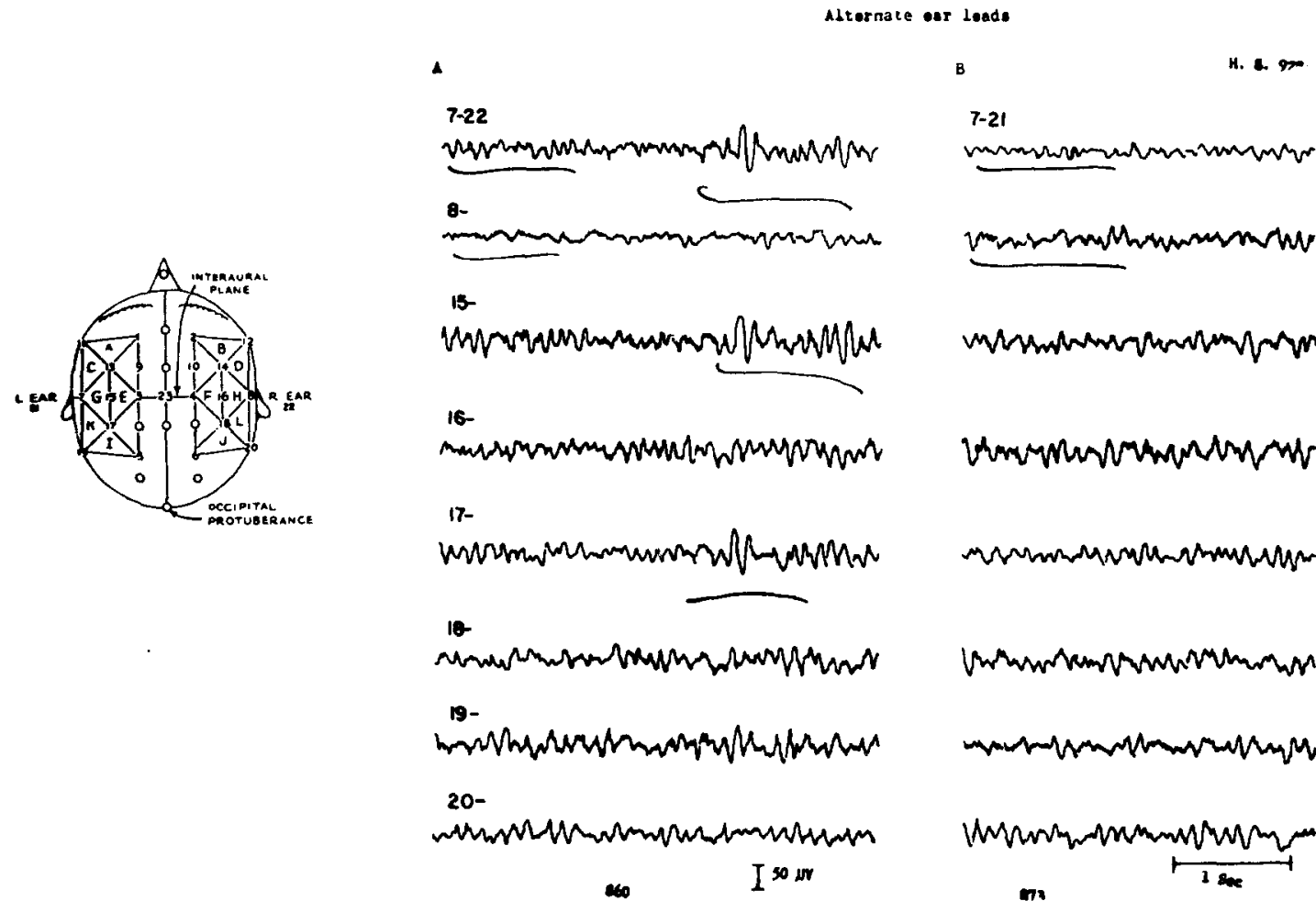

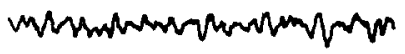

Marumunumusurys

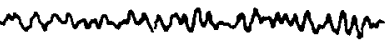

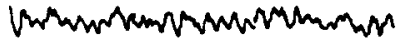

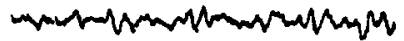

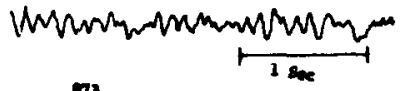

Fig. 12

Case 36. Large right cerebellar hemangioblastoma. Age 37, clear sensorium, no papilledema and moderate ventricular dilatation. A. Background alpha voltage higher in lead 7 than 8 and bursts higher in leads $7,15,17$, and 19 than in $8,16,18,20$ with right ear lead 22 reference (strips 1, 3, 5 and 7). B. Practical equalization of background voltage especially in leads 7 and 8 with left ear lead reference 21, indicating voltage gradient in left hemisphere (see figure $10 \mathrm{~B}$ and explanation). Bursts are not represented here as in $A$. This case shows much aipha positivity in frontals and motors, mild single 5 to $8 / \mathrm{sec}$. bursts bilaterally, mild left temporo-parietal bursts, left sided background voltage increase and rare shift of these phenomena to the right. No significant characteristic except background voltage increase and mild single bursts is shown here.

A control series of 49 verified, unverified or urrelated cases is considered in addition to a large amount of other clinical material.

2. Abnormal EEGs were found in 32 of the 37 cases. The following conclusions appeared justified: out of 28 lesions of the cerebellar hemispheres.

(c) A moderate to large proportion of cases showed bilateral synchrony, anterior and/or posterior parasagittal concentration, shift, inter-areal asynchrony and intra- 
areal variability of burst activity in varying degrees.

(d) If the following clinical conditions are absent, namely, idiopathic convulsive
3. A comprehensive scheme of localization with a suggested posterior fossa workup is described and the factors altering the EEG in posterior fossa lesions are discussed.
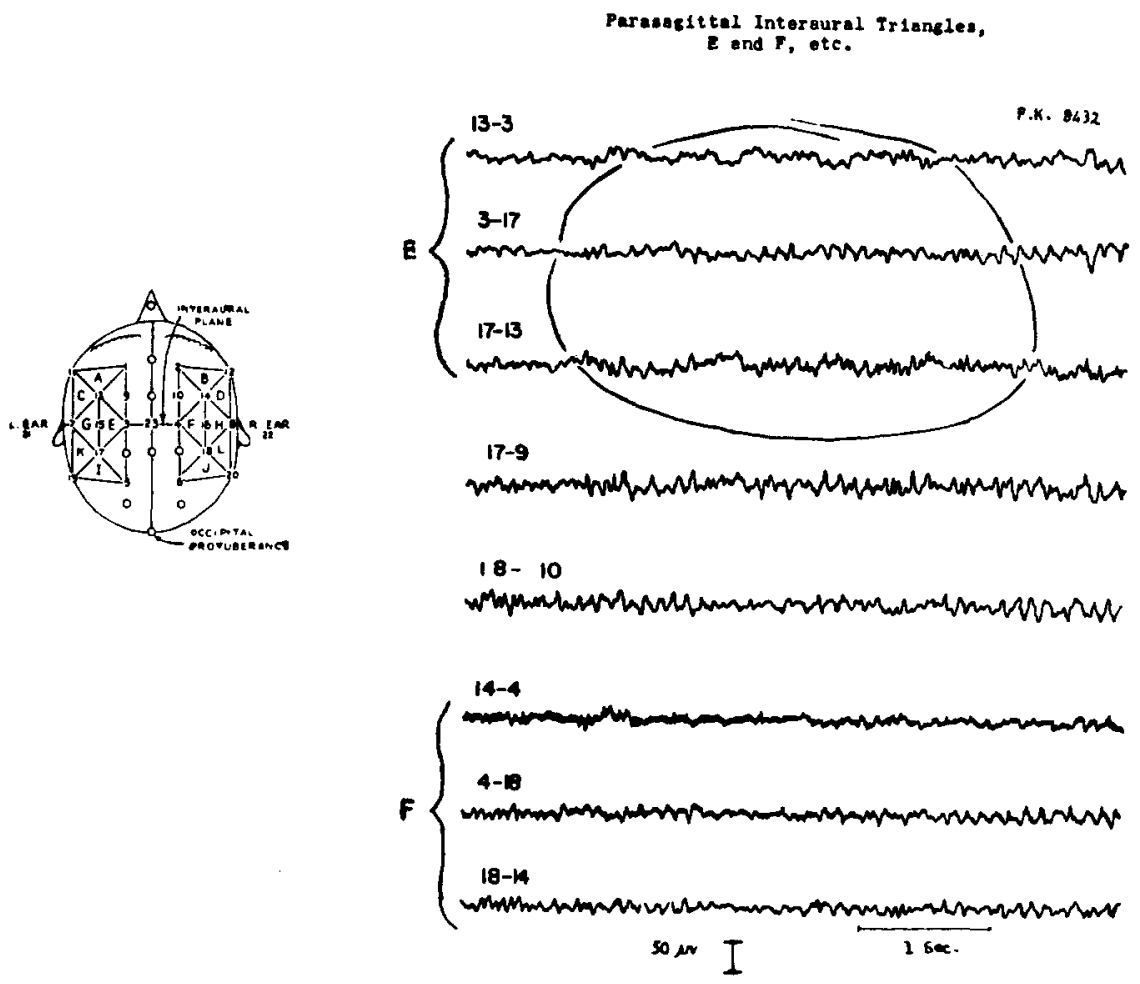

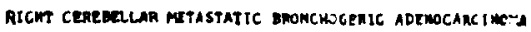

Fig. 13

Case 23. Large right cerebellar metastatic bronchogenic carcinoma. Age 42, clear sensorium, no papilledema and no ventricular dilatation. Rare low voltage undulations in the ringed left parasagittal interaural triangle $\mathrm{E}$, and bilateral bursts of $13 / \mathrm{sec}$. in both motors and premotors (not shown here) with no other significant findings. On the basis of these rare EEG findings no posterior fossa diagnosis is attempted.

disorder, temporal lobe seizure, cortical atrophy, "degeneration" with or without hypertension and acute vascular or traumatic condition. the EEG findings mentioned under $(b)$ and $(c)$ in a particular record should arouse a definite suspicion concerning the existence of a deep or posterior fossa lesion. It is emphasized, however. that a careful correlation between the clinical data and EEG should be carried out kefore the existence of such a lesion is considered in diagnosis.

\section{REFERENCES}

Bagchi, B. K.. Bassett, R. C. and Peet, M. M. A three-dimensional scheme of electroencephalographic localization of intracranial neoplasms. Trans. Amer. Neurol. Assoc., 1947, 72: 101-107.

BAgChI, B. K. and BAsSetT, R. C. Some additional electroencephalographic techniques for the localization of intracranial lesions. I. Neuro Surg., 1947, 4: 348-369.

BAGCHI. B. K. and BASSETt, R. C. The role of instrumental and genuine phase reversal in EEG localization. EEG Clin. Ncurophysiol., 1949, 1: 518.

BAssett, R. C. and BAGCH, B. K. Intracranial neoplasm localized electroencephalographically by. 
the use of a three-dimensional scheme. I. Neurosurg., 1948, 5: 298-306.

Bickford, R. B. and Baldes, E. J. The EEG in tumors of the posterior fossa. Proc. Cen. Soc. Clin. Res., 1947, 20: 87-88.

Вонм, M. Valeur prognostique de l'EEG dans les tumeurs de la fossa postérieure. Rev. Neurol. 1948, 80: 647 .

Carraro, Di V. and Gualtierotti, T. Sulle relazioni tra cerbello e cervelletto dal punto di vista elettrofisiologico. Boll. Soc. It. Biol. Sper., 1940. 15: $80-82$.

Coвв, W. A. Rhythmic slow discharges in the electroencephalogram. I. Neurol. Neurosurg. Psychiat., 1945, 8: 65.

ECKER, A. Ulpward transtentorial herniation of the brain stem and cerebellum due to tumor of the posterior fossa. I. Neurosurg., 1948, 5: 51-61.

Forster, F. M. and Nims, L. F. Electroencephalographic effects of acute increases of intracranial pressure. Arch. Neurol. Psychiat., Chicago, 1942, 47: 449-453.

Henneman, E., Cooke, P. and Snider, R. S. Cerebellar projections to the cerebral cortex in cat and monkey. Amer. J. Physiol., 1948, 155: 443.

Hoefer, P. F. A., Schlesinger, E. G. and Pennes, H. H. Clinical and electroencephalographic findings in a large series of verified brain tumors. Trans. Amer. Neurol. Assoc., 1946, 71 : $52-57$.

Holland, C. G. Changes caused by cerebellar neoplasms in the electroencephalogram. Virginia Med. Mon., 1941, 68: 459-462.

Lairy-Bounes, G. C. and Fischgold, H. L'électroencéphalographie dans une série de trente-huit tumeurs de la fossa postérieure. Sem. Hop. Paris, 1950, 26: 2633-2635.

LenNox. J. and Brody, V. S. Paroxysmal slow waves in EEGs in patients with epilepsy and with subcortical lesions. J. nerv. ment. Dis., 1946, 104: $237-248$.

Lennox, M. and Exstein, J. A. Experimental evaluation of recording to alternate ears as an aid in localization. EEG. Clin. Neurophysiol., 1950, 2: 333-337.

Lindsley, D. B., Bowden. J. W. and Magoun, J. W. Effect upon the EEG of acute injury to the brain stem activating system. EEG. Clin. Neurophysiol., 1949, 1: 475-486.
Moruzzi. G. and Magoun, H. W. Brain stem reticular formation and activation of the EEG. EEG. Clin. Ncurophysiol., 1949, 1: 455-473.

Rheinberger, M. B. and Davidoff, L. M. Posterior fossa tumors and electroencephalogram. $1 . \mathrm{Mt}$. Sinai Hosp., 1942, 9: 734-754.

Scarff, J. E. and RaHM, W. E. Jr. The human electrocorticogram. J. Neurophysiol., 1941, 4: $418-426$

Smith, J. R., Walter, C. W. P. and Laidlaw, R. $W$. The electroencephalogram in cases of neoplasms of the posterior fossa. Arch. Neurol. Psychiat., Chicago, 1940, 43: 472-487.

Snider, R. S., Magoun, H. W. and McCulloch, W. S. A suppressor cerebello-bulbo-reticular pathway from anterior lobe and paramedian lobules, Fed. Proc., 1946-47, 5-6: 207.

Stewart, W. A. Electroencephalographic changes associated with different forms of experimentally produced increased intracranial pressure. Johns Hopkins Bull., 1941, 69: 240-265.

Walker, A. E. An oscillographic study of cerebellocerebral relationships. I. Neurophysiol., 1938, 1: 16-23.

Walker, A. E. Early diagnosis of brain tumor. III. Med. J., 1941. 80: 286-292.

Walter. W. G. The location of cerebral tumours by electroencephalography. Lancer, 1936, 2: 305-308.

Walter. W. G. The electroencephalogram in cases of cerebral tumor. Proc. F. Soc. Med., 19361937, 30: $579-598$.

Walter, W. G. The technique and application of electroencephalography. I. Neurol. Psychiat. 1938, $l: 359.385$.

Walter, W. G. and Dovey, V. J. Electroencephalography in cases of subcortical tumour. $I$. Neurol. Neurosurg. Psychiat., 1944, 7: 57-65.

Willams, D. and Gibbs, F. A. The localization of intracranial lesions by electroercephalography. New Eng. J. Med., 1938. 218: 998-1002.

Willams, D. The abnormal cortical potentials as sociated with high intracranial pressure. Brain, 1939. 62: 32 I-334.

Witwer, E. R., Derbyshire, A. J. and Corrigan. K. E. Applications of some new techniques to study of brain tumors. Radiology. 1943. 41: $130-141$.

Reference: BAGCHI, B. K., LAM, R. L... Kool, K. A. and BAsSETt, R. C. EEG findings in posterior fossa tumors. EEG Clin. Neurophysiol., 1952, 1: 23-40. 